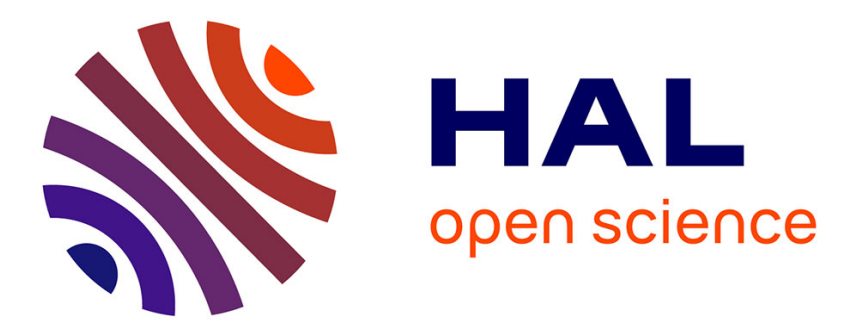

\title{
PULSED MULTICHANNEL RAMAN SPECTROMETRY OF TRANSIENT STATES
}

\author{
G. Buntinx, M. Bridoux, A. Deffontaine, O. Poizat
}

\section{To cite this version:}

G. Buntinx, M. Bridoux, A. Deffontaine, O. Poizat. PULSED MULTICHANNEL RAMAN SPECTROMETRY OF TRANSIENT STATES. Journal de Physique Colloques, 1987, 48 (C7), pp.C7-711C7-715. 10.1051/jphyscol:19877175 . jpa-00226999

\section{HAL Id: jpa-00226999 https://hal.science/jpa-00226999}

Submitted on 1 Jan 1987

HAL is a multi-disciplinary open access archive for the deposit and dissemination of scientific research documents, whether they are published or not. The documents may come from teaching and research institutions in France or abroad, or from public or private research centers.
L'archive ouverte pluridisciplinaire HAL, est destinée au dépôt et à la diffusion de documents scientifiques de niveau recherche, publiés ou non, émanant des établissements d'enseignement et de recherche français ou étrangers, des laboratoires publics ou privés. 


\title{
PULSED MULTICHANNEL RAMAN SPECTROMETRY OF TRANSIENT STATES
}

\author{
G. BUNTINX, M. BRIDOUX, A. DEFFONTAINE and O. POIZAT* \\ LASIR, CNRS LP. 2641, Université des Sciences et Techniques de \\ Lille-Flandres-Artois, Bâtiment C.5, F-59655 Villeneuve-d'Ascq \\ Cedex, France \\ * LASIR, CNRS IP. 2631, 2, Rue Henrt Dunant, BP 28. \\ F-94320 Thiais, France
}

Spontaneous Raman spectroscopy is a nonperturbing diagnostic tool that provides detailed structural information about molecules through the vibrational-line positions and intensities. Because of many specific properties, pulsed Raman spectroscopy can provide valuable information in situations in which ultrarapid recording of the vibrational spectra is of crucial importance.

The conventional monochannel spectrometry technique using scanning monochromators allows recording the luminous intensity as a function of wavelength for a static sample or the intensity as a function of time if the monochromator works at fixed frequency. It is clear that the monochannel technique is inadequate for pulsed Raman spectroscopy because the probability of detection of a rapidly changing or of a random event is inevitably very weak. On the other hand, in the multichannel technique, all of the spectral elements are simultaneously recorded, leading to the recording of intensity versus wavelength and time (1).

The development of time-resolved Raman spectroscopy is connected :

- to progresses in the technology of multichannel detectors;

- to improvements to spectrographs which should present good luminosity and resolution, superb stray light rejection while passing a wide band of frequencies (2) ;

- to improvements to pulsed lasers, especially stability, repetition rate and beam quality.

\section{PULSED MULTICHANNEL RAMAN SPECTROMETRY : PRINCIPLE AND TECHNIQUE}

The principle of pulsed multichannel Raman spectrometry is sketched on Fig. 1 . The laser beam is focused onto the sample. The light scattered at right angle to the laser beam is collected with a lens and focused onto the entrance slit of a grating spectrograph. The resulting spectrum is focused onto the photocathode of an image intensifier phototube. The intensified spectrum which appears on the phosphor screen is transferred onto the photocathode of a SEC or SIT vidicon tube, or onto a photodiode array where the spectrum is converted in an electronic image and stored. Data processing of the video signal can then be performed. 


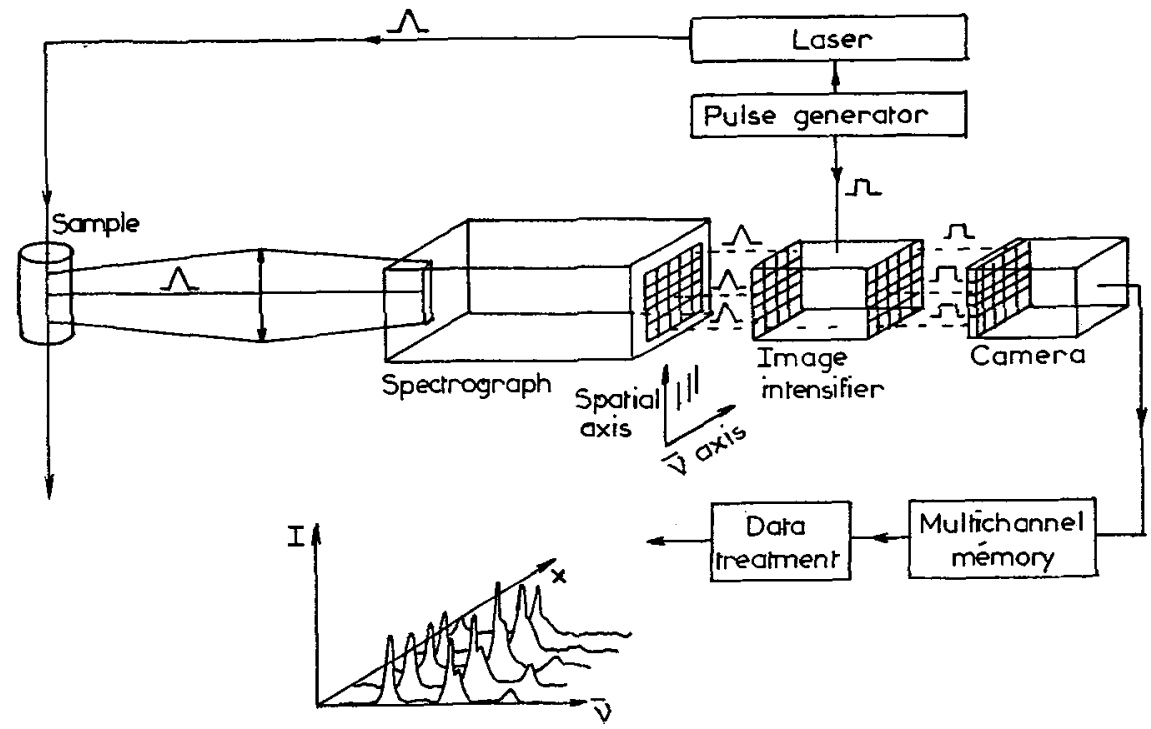

Fig. 1 : Pulsed multichannel Raman spectrometry

A carefull design of the spectrograph gives rise to a good stigmatism in the spectral region of interest and also in a direction parallel to the entrance slit. This last point is very important because one can then take advantage of the feasibility of spatial analysis of the sample. Image intensifiers and $T V$ camera tubes allow the analysis of a great number of pictural elements (pixels) of the spectral image. By looking at the spectral image focused in the focal plane of an ideal polychromator, the location of a signal in a pixel of this image gives two kinds of information.

The location of the signal along the horizontal axis (i) gives the frequency of the molecular vibrator which is detected.

The location of the signal along the vertical "spatial" axis gives the position of the vibrator in the sample.

Practical points of prime importance in time-resolved Raman spectroscopy have to be considered with much care :

- synchronisation between the laser and the detectors gating : in luminous environments pulsed excitation of the sample and gating of the detector is required to produce and detect a number of Raman photons larger than the number of spurious photons;

- synchronisation between the perturbation and the laser shot in the case of a pump-then-probe experiment ;

- control of the laser power density inside the sample to avoid non-linear effects. 
Most chemical or biological processes have their first steps in the picosecond or nanosecond range. We have demonstrated that the multichannel Raman technique permits recording of the spontaneous Raman spectrum excited by a $25 p s$ pulse from a mode-locked frequency-doubled YAG laser (3).

\section{SOME APPLICATIONS OF PULSED MULTICHANNEL RAMAN SPECTROMETRY}

\section{II.1. Combustion phenomena inside an engine}

Pulsed multichannel Raman technique has been applied to the analysis of the combustion phenomena inside the combustion chamber of an engine. The laser shot is synchronized with the rotation of the engine and Raman spectra are recorded for different crank angles. Spatial analysis of the instantaneous distribution of molecular species inside the irradiated volume and temperature measurements (determined from the intensity ratio of the hot bands to the fundamental band of nitrogen) give important informations about the heterogeneous distribution of the gases. This heterogeneity is correlated to the flame front propagation and to turbulence phenomena (4).

\section{II.2. Vibrationnally excited states}

Vibrationnally excited nitrogen in its ground electronic state is very reactive. It is involved in the physics and chemistry of the upper atmosphere and more generally in all gas-phase energy transfers and chemical reactions in which nitrogen is involved. Pulsed Raman spectroscopy is a suitable method for probing vibrationnally excited species in a microwave discharge because the technique allows an efficient discrimination against the luminescence of the medium. The Raman Stokes spectrum of nitrogen at a pressure of 20 torr is obtained by averaging 20 laser pulses of $900 \mathrm{~mJ}$ (15ns duration) (Fig. 2). 5 hot bands are unambiguously identified and their profiles indicate that the molecules are far from equilibrium state (5).

\section{II.3. Electronically excited states (pump-then-probe technique)}

One method of creating a time delay between the pump and the probe pulses is with an optical delay line. This requires only one laser and a beam splitter to divide the laser output into two beams, one of which (the pump) is directed to the sample, while the other (the probe) travels a longer route. A path difference between the two beams of $0.3 \mathrm{~m}$ corresponds to a time delay of 1 ns.

The excited species and the transients may be generated phatolytically but also by other methods such as T-jump (laser generated) or pulse radiolysis for instance. An interesting feature of the: Raman imagery technique is connected with the use of multipass optical delay lines, which permits the simultaneous recording of several time-resolved Raman spectra with a single laser pulse (6). 


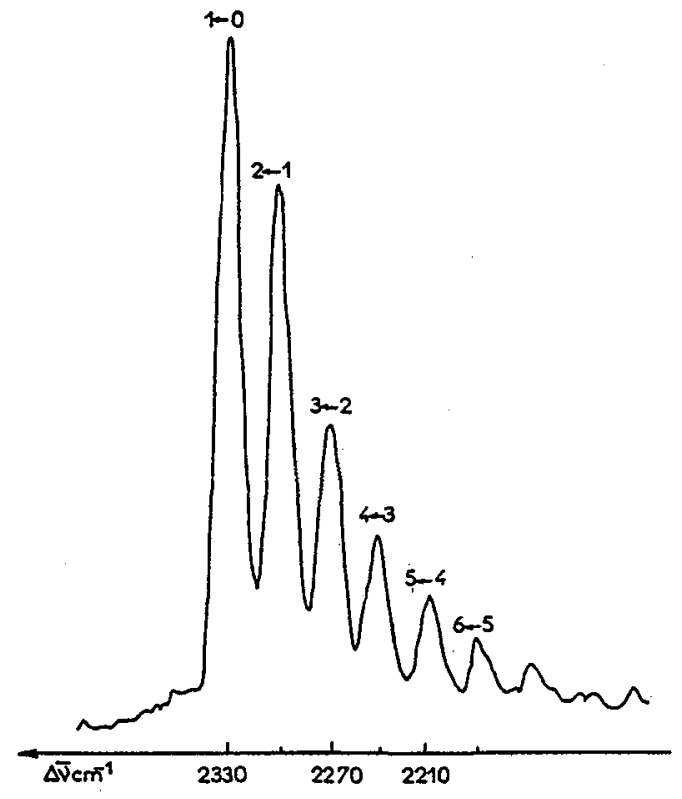

Fig. 2 : Raman Stokes spectrum of vibrationnally excited nitrogen in a microwave discharge ( $P=20$ torr).

The multichanrel Raman spectrometer which is an integrating device is able to store the results of several experiments and enhances the detectability of the system. Another way to increase the sensitivity is to use the resonance Raman spectroscopy which enhances the Raman lines when the exciting laser. line is within an absorption band. In cases of resonance, it is possible to record Raman spectra of dilute solutions in the $\left(10^{-3}-10^{-5}\right) M / l$ range.

The effectiveness of the Raman imagery technique developped in our laboratory is illustrated by the study of the triplet state of all-trans retinal (7). The same Q-switched Nd : YAG Laser (Quantel NG 24) is used for the pump (third harmonic at 355nm) and the probe (second harmonic at $532 \mathrm{~nm}$ ), which are separated and then temporally delayed by an optical delay line. In the sample cell, which is $10 \mathrm{~mm}$ long, the concentration of retinal in hexane $\left(10^{-3} \mathrm{M}\right)$ is such that the photolyzing beam is completely absorbed after a $3 \mathrm{~mm}$ travel (Fig. 3). On the spectral image one observe two different parts corresponding to a perturbed and a non-perturbed sample. Freezing this spectral image and analyzing separately its two parts gives two different spectra from which the Raman spectrum of the triplet state of trans-retinal can be obtained.

The same technique of pump-then-probe has been used for the structural investigation of the excited triplet states of aromatic diamines by resonance Raman spectroscopy (see Poster Session). 


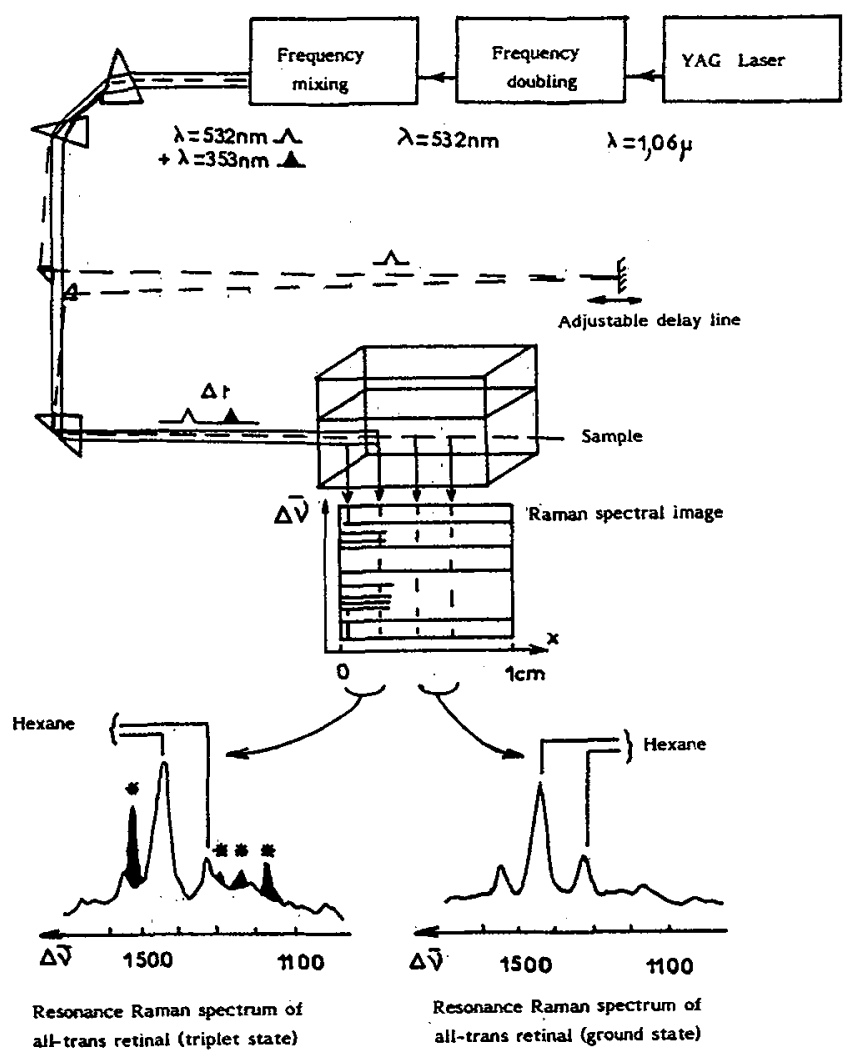

Fig. 3 : Application of the Raman imagery technique to the spectroscopy of excited electronic states

\section{REFERENCES}

1. - M. BRIDOUX, M. DELHAYE, Advances in Infrared and Raman Spectroscopy vol. 2 (R.J.H Clark, R.E Hester eds) Heyden, Londres (1976).

2. - A. DEFFONTAINE, M. BRIDOUX, M. DELHAYE, E. DA SILVA, W. HUG Rev. Phys. Appl. 19 (1984) 415-421.

3. - M.BRIDOUX, A. DEFFONTAINE, C. REISS, C.R. Acad. Sci., 282 (1976) 771.

4. - D. DESENNE, G. BUNTINX, M. CRUNELLE-CRAS, M. BRIDOUX, J.P. SAWERYSYN, L.R. SOCHET : Entropie (to be published).

5. - J.M. BENY, M. BRIDOUX, G. BUNTINX, A. CHAPPUT, M. CRUNELLE-CRAS, A. DEFFONTAINE, O. DESSAUX, B. MUTEL, Raman Spectroscopy (Lascombe et Huong Eds) Wiley-Heyden, p. 231 (1982).

6. - A. DEFFONTAINE, M. DELHAYE, M.BRIDOUX, Time-resolved Raman spectroscopy (A. Laubereau, M. Stockburger, Eds) Springer Verlag, p. 20, 1985.

7. - A. DEFFONTAINE, A. CHAPPUT, G. BUNTINX, M. BRIDOUX, Spectros. Int. J. 2, 69 (1983). 